\title{
Ultrastructural changes of the peripheral nerve induced by vibration: an experimental study
}

\author{
S T HO,' H S YU ${ }^{2}$
}

From the Department of Industrial Safety and Hygiene,' Chia-Nan Jr College of Pharmacy, Tainan, 71710, and Graduate Institute of Medical Sciences, ${ }^{1}$ and Department of Dermatology, ${ }^{2}$ Kaohsiung Medical College, Taiwan, Republic of China

ABSTRACT To investigate the effects of vibration on the peripheral nerves, rabbits were exposed to vibration of 60 cycles $/ \mathrm{s}$ frequency with $0.35 \mathrm{~mm}$ amplitude (acceleration: $51 \mathrm{~m} / \mathrm{s}^{2}$ ) for two hours daily. After 150, 250, 450, and 600 hours vibration, thin sections of the saphenous and median nerves were examined under the electron microscope. Vibration was found to induce the following changes: (1) disruption of the myelin sheath and constriction of the axon, (2) accumulation of vacuoles in the nodal gap and paranodal region, (3) disorganisation of the paranodal end loops and detachment of the paranodal end loops from the axolemma, (4) dilatation of the Schmidt-Lanterman incisures (SLI) and increased density of SLI, and (5) disappearance of neurotubules and neurofilaments in axons. The diameters of myelin sheaths disrupted by vibration varied from 2 to $12 \mu \mathrm{m}$. The extent of the myelin disruption is proportional to the vibration dose.

A worker occupationally exposed to vibration may eventually develop the so called vibration syndrome that consists of disturbances in the peripheral nerves, the peripheral circulation, muscles, bones, and joints. ${ }^{1-6}$ The patients' main complaints relating to the peripheral nerve are of paresthesia and pain in the hand. ${ }^{2457}$ Objective examination shows involvement of the peripheral nerves of the arms and comprises (1) decreased nerve conduction velocity $(\mathrm{NCV})^{247-9}$; (2) raised pain, vibration, two point discrimination, and depth sense thresholds of the fingers ${ }^{40-14}$; (3) diminished muscle tendon reflex ${ }^{4}$; and (4) neuropathic abnormalities in electromygraphy. ${ }^{15}$ Present clinical evidence indicates that the neurological component of the hand arm vibration syndrome develops first ${ }^{16}$ with a significant dose effect correlation between "the NCV, vibratory sense threshold, pain threshold" and "total operating time."17

Previous studies have shown that vibration may produce histopathological changes in the peripheral nerves of rabbits. ${ }^{1819}$ Finger biopsy and postmortem tissue specimens of exposed workers also showed neurological changes, primarily in the mechanoreceptors and peripheral nerve fibres. ${ }^{2021}$ There have been no reports, however, on the ultrastructural

Accepted 14 March 1988 changes in the peripheral nerve fibres in animals exposed to vibration.

The purpose of the present study was to study the ultrastructural pathological changes in the peripheral nerves of rabbits induced by vibration.

\section{Materials and methods}

\section{SUBJECTS AND EXPOSURE}

Twenty male albino adult rabbits aged 7 months weighing $2 \cdot 8-3.2 \mathrm{~kg}$ were used in the study. The room temperature was $28^{\circ}-33^{\circ} \mathrm{C}$ in summer and $20^{\circ}-25^{\circ} \mathrm{C}$ in winter. The apparatus for vibration exposure was a self made electromagnetic shaker producing vertical sinusoidal vibration. Frequency was fixed at 60 cycles/s, amplitude at $0.35 \mathrm{~mm}$ (root mean square). Vibration acceleration was $51 \mathrm{~m} / \mathrm{s}^{2}(5 \cdot 1 \mathrm{G})$. Rabbits were divided into five groups, each consisting of four animals. Group 5 was the control group. Groups 1, 2, 3 , and 4 were subjected to vibration for $150,250,450$, and 600 hours respectively. Each rabbit was put into a box with its head through a hole on the upper side of the box to prevent the animal from lying down. The bottom of the box was removed so that the rabbit could stand on the shaker. In this way vibration was transmitted mainly to the four legs and to a lesser extent to the whole body. Rabbits were exposed to vibration for two hours daily for six days a week. Each control rabbit was put into a box, placed near the 
operating shakers, and exposed to noise for 150,250 , 450 , and 600 hours respectively. The noise exposure level was $69 \mathrm{~dB}$ for the test rabbit and $67 \mathrm{~dB}$ for the control rabbit environment. Control rabbits were killed on the same day as the four test groups.

\section{ELECTRONMICROSCOPIC EXAMINATION}

After $150,250,450$, or 600 hours of exposure the animals were anaesthetised with sodium pentobarbital $(30 \mathrm{mg} / \mathrm{kg}$, intravenously) and the median nerve and saphenous nerve were exposed and fixed in situ with $2 \%$ glutaraldehyde (containing $1.5 \%$ formaldehyde) in $0.1 \mathrm{M}$ Cacodylate buffer ( $\mathrm{pH} \mathrm{7.4)}$ ) for 30 minutes. The nerves were cut into $1 \mathrm{~mm}^{3}$ pieces for further two hours fixation and postfixed with $1 \%$ osmium tetroxide for two hours. After postfixation specimens were dehydrated and embedded in Epikote (Merck, West Germany). Thin cross or longitudinal sections made by diamond or glass knives and stained with uranyl acetate and lead citrate were examined under a Hitachi H-500 electron microscope.

\section{DIAMETERS SPECTRA AND FREQUENCY OF MYELIN} DISRUPTION

The diameters of the nerve fibres were determined in the cross sections of saphenous nerves according to the method of McDonald. ${ }^{22}$ In brief, cross sections of $\frac{\$}{\infty}$ saphenous nerves were mounted on single slot grids supported by a Formvar film. Each cross section was photographed in its entirety by electron microscopy. Micrographs for analysing the diameter of nerve fibres were made with a total magnification of $\times 3800$. Micrographs of a fascicle were mounted together to make each montage. The diameter was calculated from measurements of the area of fibre profiles by area $s$ curvimeter (Keuffel \& Esser Co, West Germany). This $\vec{\circ}$ method was adopted because many fibres were irregular in outline and rendered the point to point measurement of diameter meaningless. Total count and density of myelinated fibres of saphenous nerves of rabbits subject to vibration for 600 hours (test rabbits) and those of control rabbits were calculated. The diameter distribution in test rabbits showed 755 fibres with their sheaths severely disrupted and 1617 o with their sheaths intact. In control rabbits nerve fibre diameter spectra were made from 2423 fibres. To elucidate the frequency of myelin disruption, several fields with a total number of 200 fibres were randomly selected from the cross sections of the saphenous nerve trunk of each rabbit. Myelin sheaths severely disrupted were calculated and expressed as percentage of 200 fibres. Mean and standard deviation were made from four rabbits of each group.

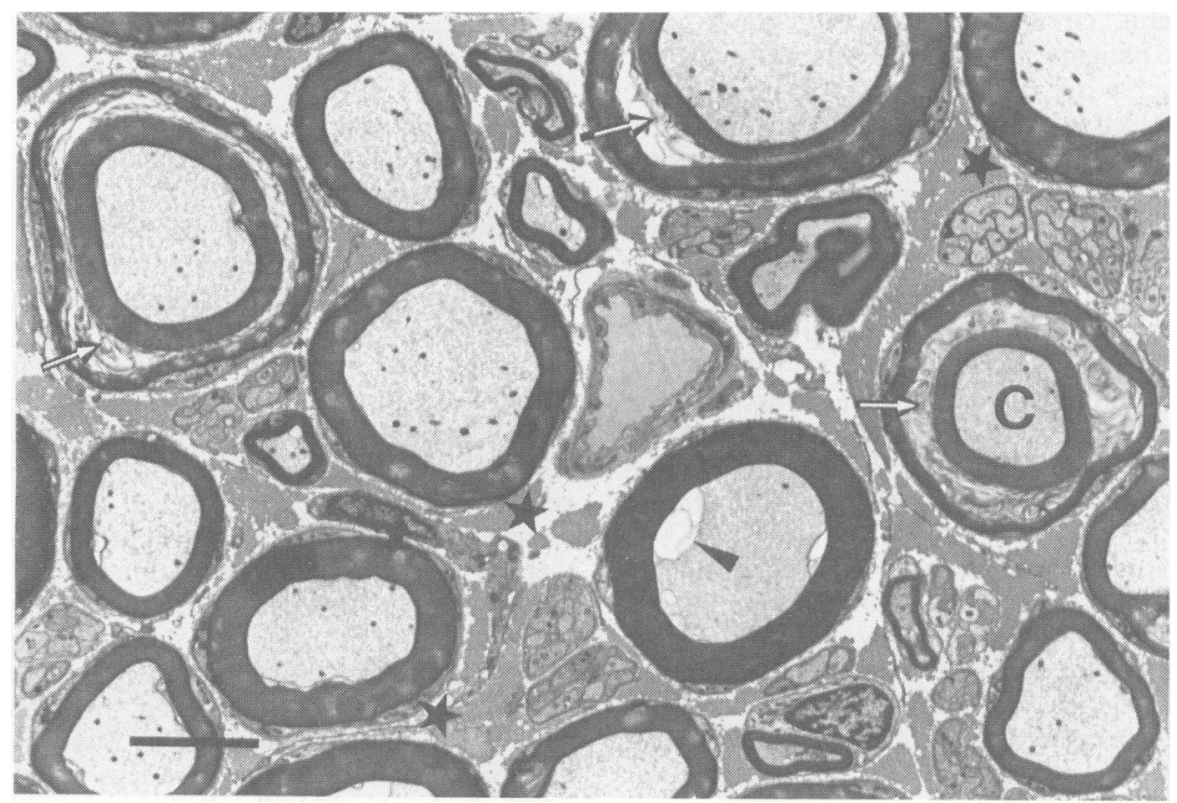

Fig 1 Cross section of saphenous nerve after 450 hours vibration. Several sheaths were disrupted (arrows), one sheath associated with axonal constriction $(C)$. Other sheaths detached with axon (arrowheads). Some other sheaths showed patchy loss of density (stars). Scale bar: $5 \mu \mathrm{m}$. 


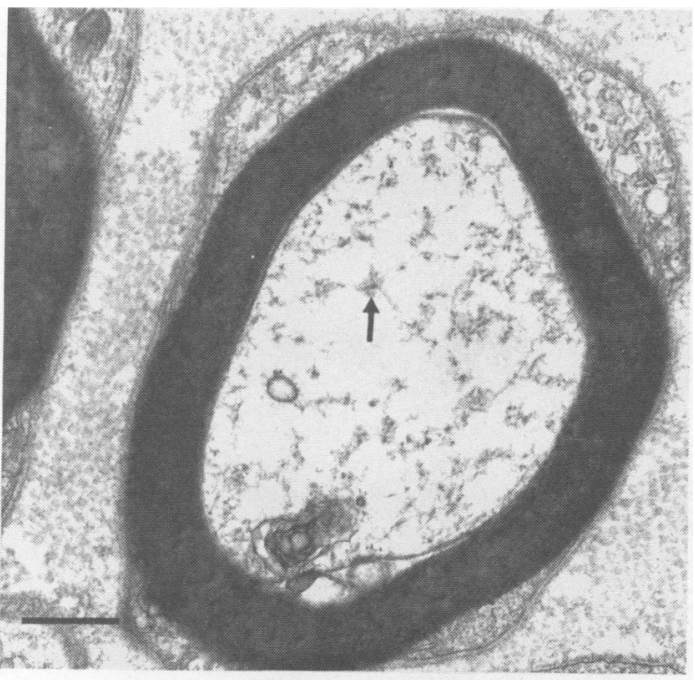

Fig 2 Cross section of median nerve after 600 hours vibration. Neurotubules and neurofilaments disappeared in axon and were substituted by fluocculent materials (arrow). Scale bar: $0.6 \mu \mathrm{m}$.

\section{Results}

\section{ULTRASTRUCTURAL CHANGES OF THE MYELIN SHEATH AND THE AXON}

There was no difference between the median nerve (mixed motor and sensory nerve) and saphenous nerve (pure sensory nerve) in the pattern of vibration induced ultrastructural changes. The sheaths of nerve fibres in control rabbits were intact. The main changes of the nerve fibres induced by vibration were as follows: (1) disruption of the sheath, (2) detachment of the sheath from the axon, (3) patchy loss of density in the sheath, (4) severe constriction of the axon, and (5) protrusion of the sheath into the axon (fig 1). The higher the vibration dose, the more severe the destruction. After 150 hours vibration only a few fibres showed slight disruption of the sheath and detachment of the sheath from the axon. When the vibration time was over 450 hours, several sheaths showed patchy loss of density and some axons were severely constricted (fig 1). Myelin like debris was frequently observed in the cytoplasm of Schwann cells. This appeared as rod like or spirally wound layers of loosely arranged membrane profiles. Disappearance of neurotubules and neurofilaments, a clear indication of degeneration, also occurred in some non-myelinated and myelinated axons (fig 2). Destroyed neurotubules and neurofilaments were substituted by flocculent materials. Myelinated and non-myelinated fibres of the skin of the toe showed changes similar to those in the saphenous nerve. Figure 3 shows a thin section of a node of Ranvier of a control saphenous nerve. Numerous end loops of Schwann cell cytoplasm (L) bracketed the nodal membrane (N). The axonal membrane was divisible into three regions - the nodal membrane $(N)$, the paranodal region $(P)$, and the interparanodal region (IP). Between the basal lamina (B) and the nodal axon was the gap substance. Embedded in the gap substance were the finger like microvilli (V) of Schwann cell. After 450 hours vibration (fig 4), some vacuoles had accumulated in the nodal gap. The paranodal end loops appeared irregularly and some loops detached with the paranodal axolemma. The sheath of interparanodal region was also detached with the axolemma. By 600 hours vibration (fig 5), the paranodal end loops were disorganised and many vacuoles had accumulated in the nodal gap and the paranodal region; the Schwann cell microvilli were covered by these vacuoles. Most paranodal end loops detached with the axolemma and formed free end loops or whorl like debris.

\section{ULTRASTRUCTURAL CHANGES OF SCHMIDT- LANTERMAN INCISURE}

The Schmidt-Lanterman incisure (SLI) from a control saphenous nerve was usually closed or slightly open and cytoplasmic spirals appeared regularly. Near the surface of the fibre (abaxonal side) many incisures presented characteristic stacks of desmosomoid structures. Usually, there are 20 pairs of SLI in a length of 1 mm. ${ }^{23}$ Vibration caused dilatation of incisures from the adaxonal side and increased their density. After 250 hours vibration the incisure dilated from the adaxonal side bilaterally. By 450 hours vibration, in

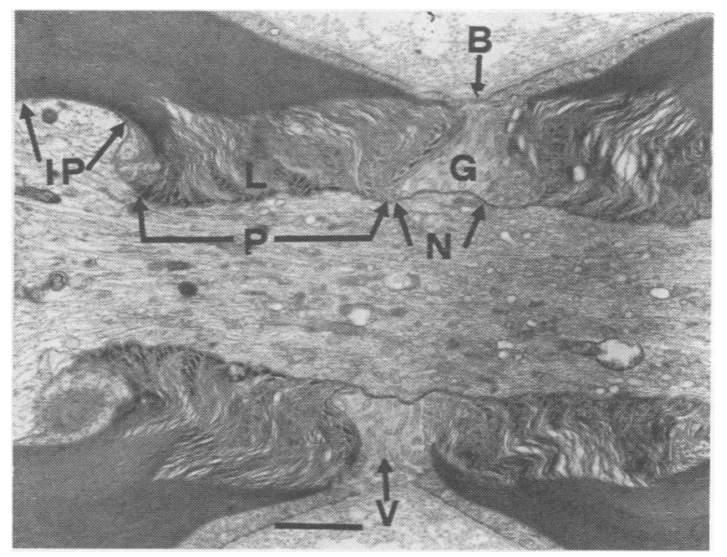

Fig 3 Longitudinal section of control saphenous nerve through mode of Ranvier. $N=$ Node of Ranvier, $P=$ paranode, $I P=$ interparanode, $V=$ Schwann cell microvilli, $B=$ basal lamina, $G=$ nodal gap,

$L=$ paranodal end loops. Details see text. Scale bar: $1 \mu \mathrm{m}$. 


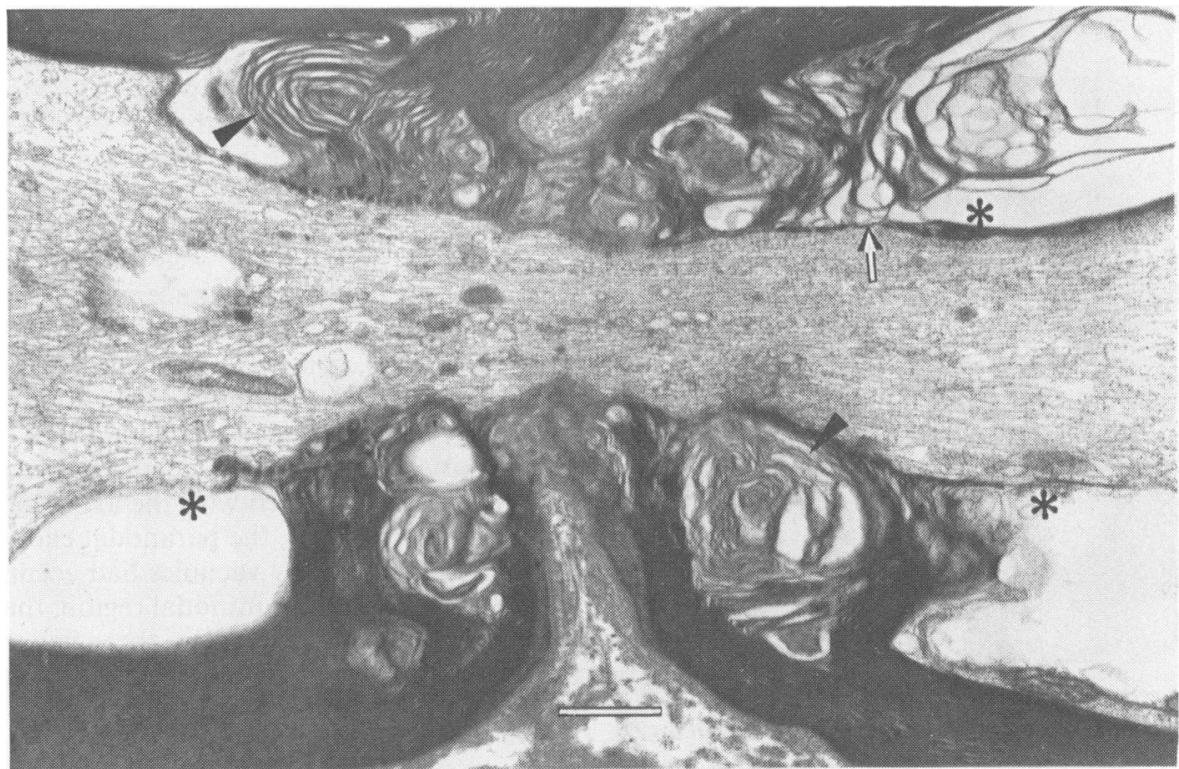

Fig 4 Longitudinal section of saphenous nerve through node of Ranvier after 450 hours vibration. Paranodal end loops appeared irregularly (arrowheads). A few paranodal end loops detached with axolemma (arrow). Interparanodal sheath also detached with axon (asterisks). Scale bar: $1 \mu \mathrm{m}$.

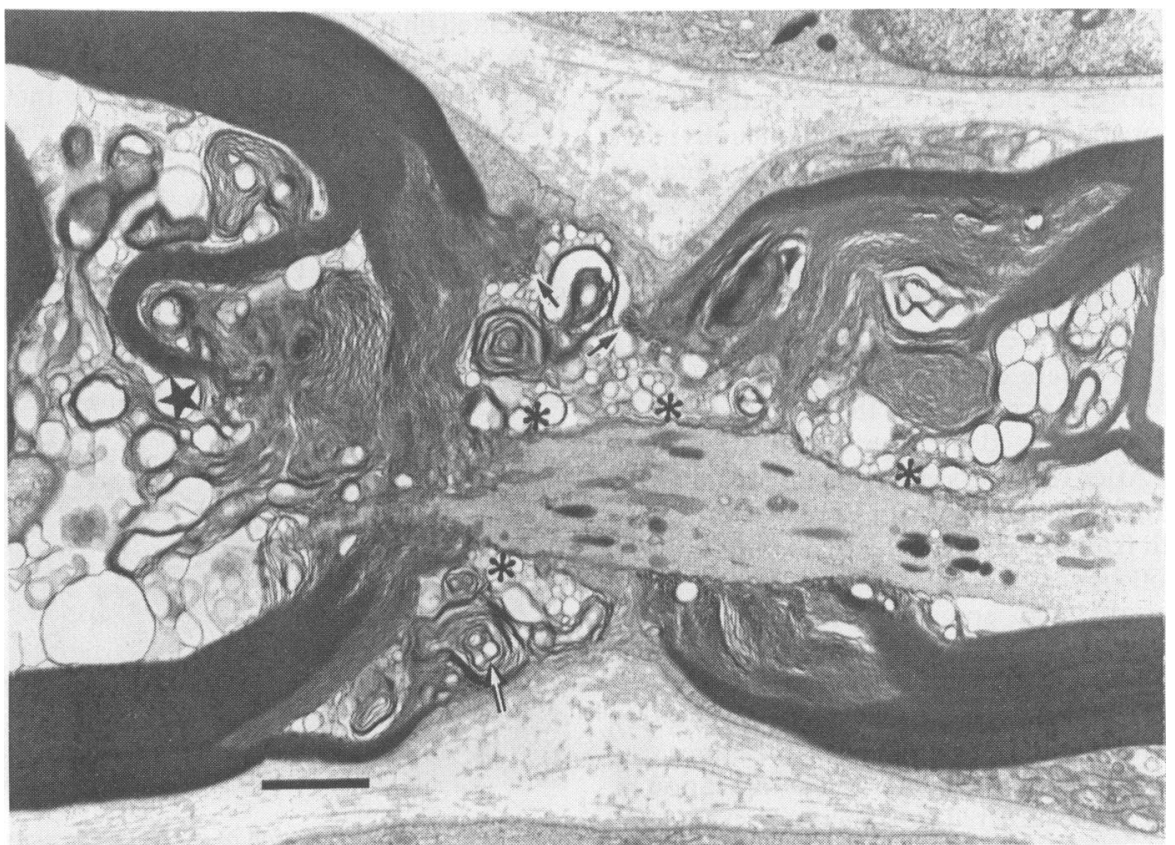

Fig 5 Longitudinal section of median nerve through node of Ranvier after 600 hours vibration. Paranodal end loops were disorganised (star) and some end loops formed whorl like myelin debris (arrow). Many vacuoles accumulated in nodal gap and paranodal region. Most end loops detached with axolemma (asterisks) and became free (arrowheads). Scale bar: 1 um. 


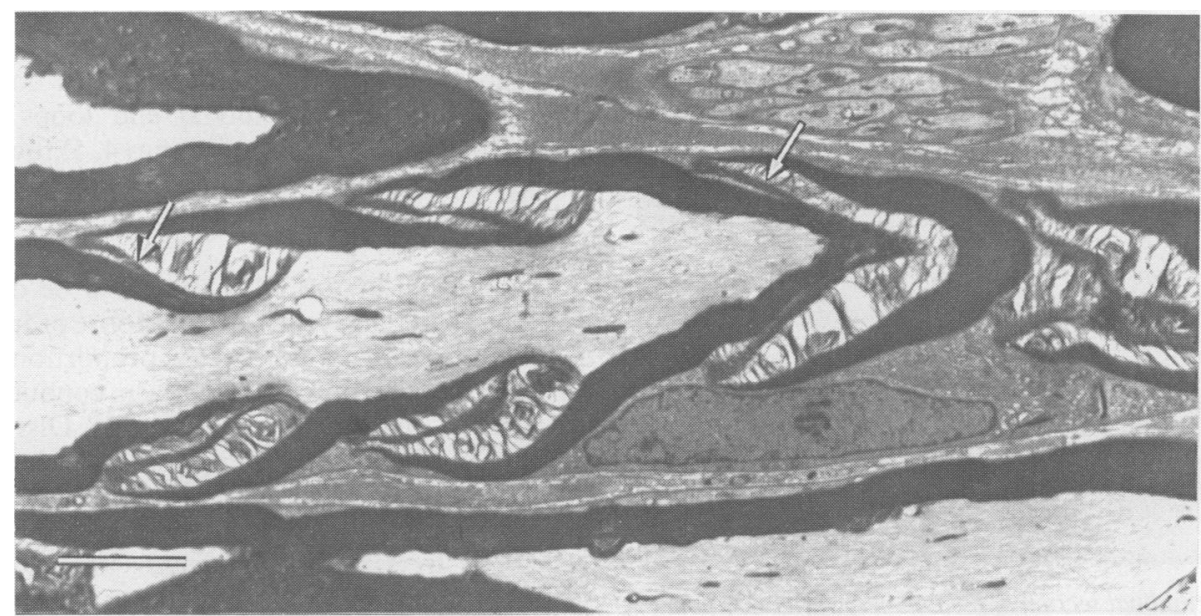

Fig 6 Longitudinal section of median nerve after 600 hours vibration. Density of SLI increased. In a length of 44 um there were four pairs of SLI. SLI severely dilated. Cytoplasmic spiral (arrow) appeared clearly. Scale bar: $5 \mu \mathrm{m}$.

addition to dilatation, the density of the incisure increased. In a length of $31.3 \mu \mathrm{m}$ there were three pairs of SLI. By 600 hours vibration, the density of incisure also increased (fig 6). In a length of $44 \mu \mathrm{m}$ there were four pairs of SLI. Meanwhile, peri-incisural myelin disrupted due to severe dilatation (fig 7).

\section{FIBRE DIAMETER SPECTRA AND FREQUENCY OF MYELIN DISRUPTION}

The saphenous nerve from two control rabbits consisted of an average of 27 fascicles and contained an average of 5981 myelinated fibres at a level near the foot. The nerve fibres were packed at a density of 1.79 fibres per $100 \mu \mathrm{m}^{2}$ of cross sectional area of nerve. The size distribution of 2423 myelinated fibres measured from the saphenous nerve of the control rabbits is shown in fig $8 \mathrm{~b}$. The saphenous nerve from two test rabbits subjected to 600 hours vibration consisted of 28 fascicles and contained an average of 5903 myelinated fibres at the same level as control; the nerve fibre density was 1.74 fibres per $100 \mu \mathrm{m}^{2}$ of cross sectional area of nerve. Of 2372 fibres measured, 1617 were sheath intact (myelin sheath not disrupted by vibration) and 755 sheath disrupted (myelin sheath severely disrupted by vibration). Their size distribution is shown in fig $8 \mathrm{a}$. The sheath disrupted fibres were from $2 \mu \mathrm{m}$ to $12 \mu \mathrm{m}$ in diameter. In addition, the difference in the size distribution from the saphenous nerve of control rabbits (fig $8 \mathrm{~b}$ ) compared with that of sheath intact fibres from test rabbits was not significant $\left(\chi^{2}(11)=16.5, p>0.05\right)$. The frequencies of myelin disruption were $5.6 \pm 0.9, \quad 10.7 \pm 1.8$, $24.1 \pm 3.5$, and $31.5 \pm 3.9$ in percentage in groups 1 , 2,3 , and 4 , respectively.

\section{Discussion}

Studies on the vibration syndrome are usually conducted in temperate or cold areas. ${ }^{149161924-26}$ In the present study, however, the temperatures of the experimental location were $20^{\circ}-25^{\circ} \mathrm{C}$ in winter and $28^{\circ}-33^{\circ} \mathrm{C}$ in summer. In this way a confounding factor-cold stress-was eliminated. The noise level was about the same in both the control and test environments and thus the only difference between the control and test groups was exposure to vibration. The vibration level of pedestal grinding, ${ }^{26}$ air grinder, ${ }^{17}$ chain saw, ${ }^{57}$ rock-drill, ${ }^{25}$ chipping hammer, ${ }^{11} 242528$ and air hammer work $^{29}$ are 2-44, 6-79, 16-200, 294, 120-351, and 2010 $\mathrm{m} / \mathrm{s}^{2}$ respectively. Thus the vibration level of this experiment was within the range of chain saw and air grinder work but much lower than that of work with a rock drill, chipping hammer, or air hammer. This experimental vibration level also surpassed the ISO/ DIS/5349 (1979) ${ }^{30}$ recommended limits for human exposure to vibration transmitted to the hand. Karpova indicated that vibration causes periaxonal change and Wallarian degeneration in nerve fibres. ${ }^{19}$ In addition to these two changes we found that vibration induces ultrastructural changes in the node of Ranvier and the SLI. The effects of vibration increase with exposure time: whereas after 150 hours vibration only a few fibres show disruption of the sheath and detachment of the sheath with the axon after 600 hours vibration the disruption of the sheath and the constriction of the axon are severe and the peri-incisural myelin of the SLI begins to disrupt. Most of the paranodal end loops detach with the axolemma. Some myelinated and non-myelinated 


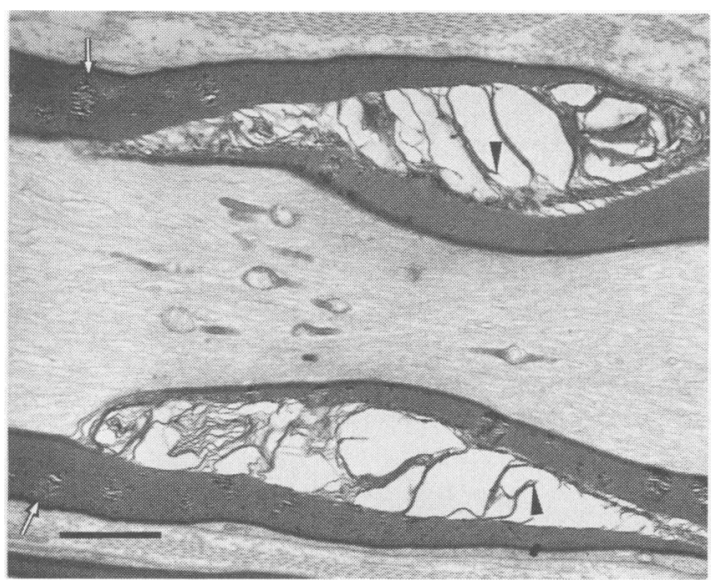

Fig 7 Longitudinal section of median nerve after 600 hours vibration. SLI was severely dilated and peri-incisural myelin disrupted (arrowhead). Sheath also showed patchy loss of density (arrows). Scale bar: $2 \mu \mathrm{m}$.

axons show loss of the neurotubules and neurofilaments. Meanwhile, destruction of the myelin sheath occurs earlier, more severely, and more frequently than that of the axon. This trend of destruction coincided with the peripheral nerve changes shown by finger biopsy in chain saw operators. ${ }^{31}$ In finger biopsy specimens the destruction and disappearance of axons occur less severely and less frequently than the loss of myelin. ${ }^{31}$ There are, however, three principal discrepancies between this study and the finger biopsy data. Firstly, pathological changes in finger biopsy specimens are in a more advanced stage of degeneration. Axons are decreased in number and sometimes disappear. In our study no significant disappearance of myelinated nerve fibres is induced by the analysis of the fibre diameter spectrum of the saphenous nerve (fig 8). Secondly, this study shows an early phase of destruction whereas a finger biopsy specimen shows only the final stage of destruction. Thirdly, there is no appreciable increase in collagen formation in our study. Takeuchi's results on finger biopsy specimens show that fibroblasts with collagen are increased not only in the endoneurium but also in the perineurium. ${ }^{31}$

It is suggested that ultrastructural changes caused by vibration are highly related to the slowing of NCV and to peripheral nervous disturbances found in workers exposed to vibration. It has been shown that rise in action potential is related to structural changes in the paranodal region. ${ }^{32}{ }^{33}$ Freeze fracture EM studies of this region show a highly ordered glial-axonal junction contributed by both the axon and the Schwann cell. ${ }^{34-38}$ Wiley and Ellisman proposed a model for the cyclic movements of $\mathrm{Na}^{+}$ions involved in saltatory conduction at the node of $\stackrel{\mathrm{D}}{\stackrel{\mathrm{D}}{?}}$ Ranvier ${ }^{38}$ Accumulation of vacuoles in the nodal gap, $\overrightarrow{\vec{F}}$ disorganisation of the paranodal end loops, and $\stackrel{\oplus}{+}$ detachment of the paranodal end loops with the axolemma caused by vibration (figs 4,5 ) found in this $\frac{\bar{O}}{\bar{N}}$ study may cripple the cyclic movement of $\mathrm{Na}^{+}$in $\frac{\bar{\sigma}}{\vec{\sigma}}$ impulse conduction, and lead to the slowing of the $\stackrel{\Phi}{\Omega}$ NCV.

The slowing of the NCV may also be due to the destruction of the myelin sheath. Moore proposed that ${ }^{\circ}$ conduction velocity is directly proportional to the $\vec{\omega}$ diameter of nerve fibre and axoplasm conductance but $\stackrel{\Phi}{ }$ inversely to membrane capacitance. ${ }^{39}$ Disruption of $\mathbb{\mathbb { D }}$ the sheath (fig 1) and patchy loss of sheath density 3 (fig 1) may decrease radial resistance and increase $\frac{\vec{\sigma}}{}$ membrane capacitance. Constriction of the axon (fig $\omega$ 1) caused by vibration decreases the axonal cross $\vec{F}$ sectional area, thus reducing the axoplasm conduc- $\gamma$ tance. Therefore, vibration induced slowing of the $\frac{}{5}$ $\mathrm{NCV}$ may be due to an increase of membrane $\vec{r}$ capacitance as well as reduction of the axoplasm $\frac{3}{2}$ conductance and radial resistance. Severe dilatation of $\bar{\alpha}$ SLI caused by vibration is an early sign of degenera- $\neg$ tion. Webster indicated that in the early phase of $\varphi_{\infty}$ Wallerian degeneration induced by crush lesion there. was a progressive increase in the total number of $\square$ incisures. ${ }^{40}$ The region of the sheath showing the greatest, progressive increase in incisures was the first $\frac{\bar{\partial}}{\partial}$ to show segmentation. Williams and Hall reported that during the early phase after nerve crush, there was $\stackrel{\mathbb{\Omega}}{\stackrel{\circ}{\circ}}$

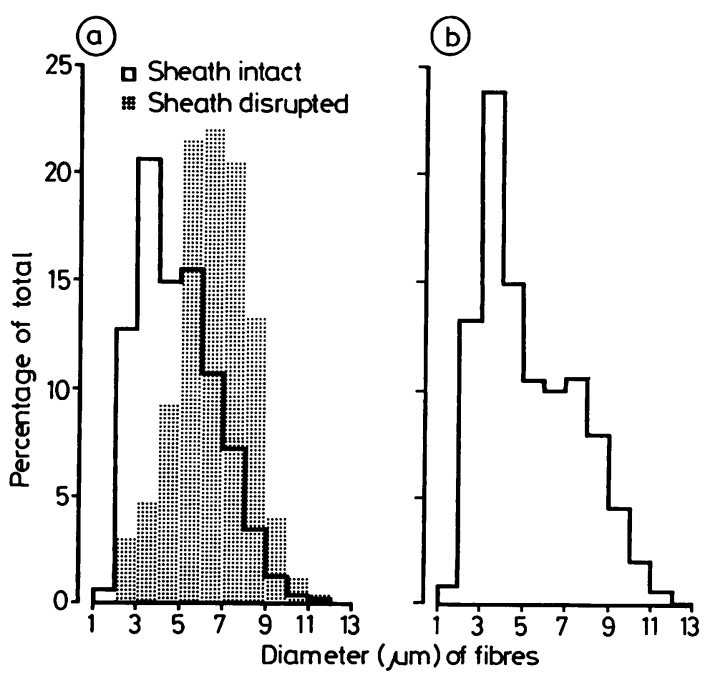

Fig 8 (a) Histogram showing size distribution of myelinated fibres in saphenous nerve $(n=2)$ after 600 hours vibration. Sheath intact fibres were compared with sheath disrupted fibres. (b) Histogram showing size distribution of myelinated fibres in control saphenous nerves $(n=2)$. 
a progressive disruption of the compact myelin sheath, the initial changes affecting the incisures and nodes. ${ }^{41}$ At the SLI, dilatation followed the widening of the incisural intraperiod line gap, splitting the intraperiod line in the peri-incisural region. In this study vibration caused dilatation and increased density of SLI and, finally, disruption of the peri-incisural myelin occurs (figs 6,7). These changes are similar to those of the early phase of Wallerian degeneration.

The analysis of fibre diameter spectra (fig 8) shows that the diameter of sheaths of disrupted nerve fibres ranged from $2 \mu \mathrm{m}$ to $12 \mu \mathrm{m}$. These sensory fibres include fibres from: (1) primary and secondary ending of muscle spindle; (2) Golgi tendon organs; (3) Pacinian corpuscles; (4) Meissner's corpuscle; and (5) carrying deep pressure, touch, and pricking pain. ${ }^{4243}$ Motor fibres include type $A^{\alpha}$ and type $A^{\gamma}$ which innervate skeletal muscle and muscle spindles. ${ }^{4243}$ Disruption of the sheaths of these motor and sensory fibres may therefore be responsible for various functional disturbances of workers exposed to vibration. The disturbances shown by objective examination include (1) raised vibration and pain threshold 10142325444 ; (2) raised two point discrimination and depth sense threshold ${ }^{1424}$; and (3) decrease of grip force, pinching power, and tapping ability. ${ }^{8264647}$ Thus the morphological finding is highly related to the functional clinical examination.

We thank the National Science Council of the Republic of China for the Research grant (No NSC77-0412-B037-12) in support of this work.

Requests for reprints to: Dr Shien-Tsong Ho, Department of Industrial Safety and Hygiene, Chia-Nan Jr College of Pharmacy, Tainan, 71710, Taiwan, Republic of China.

\section{References}

1 Seppäläinen AM. Peripheral neuropathy in forest workers. A field study. Work Environ Heath 1972;9:106-11.

2 Hisanaga $\mathrm{H}$. Studies of peripheral nerve conduction velocities in vibrating tool operator. Jpn J Ind Health 1982;24:284-93.

3 Kasamatsu T, Miyashita K, Shiomi S, Iwata H. Urinary excretion of hydroxyproline in workers occupationally exposed to vibration. Br J Ind Med 1982;39:173-8.

4 Juntunen J, Matikainen E, Seppäläinen AM, Laine A. Peripheral neuropathy and vibration syndrome: a clinical and neurophysiological study of 103 patients. Int Arch Occup Environ Health 1983;52:17-24.

5 Miyashita K, Shiomi S, Itoh N, Kasamatsu T, Iwata H. Epidemiological study of vibration syndrome in response to total handtool operating time. Br J Ind Med 1983;40:92-8.

6 Bossche JVD, Lahaye D. $x$ Ray anomalies occurring in workers exposed to vibration caused by light tools. $\mathrm{Br} J$ Ind Med 1984;41:137-41.

7 Seppäläinen AM, Starck J, Härkönen $H$. High-frequency vibration and sensory nerves. Scand J Work Environ Health 1986;12:420-2.
8 Alaranta H, Seppäläinen AM. Neuropathy and the automatic analysis of electromygraphic signals from vibration exposed workers. Scand J Work Environ Health 1977;3:128-34.

9 Dylewska D. The study of conduction in the motor and sensory nerves of upper limbs in vibration disease. Neurol Neurochil Pol 1970;4:28-31.

10 Harada N, Yamada S, Matsumoto T. Changes of the vibratory sensation threshold in workers using vibrating tools. Jap J Ind Health 1976;18:395-402.

11 Harada N, Matsumoto T. Vibration disease in an iron foundry. In: Proceedings of 9th Asian Conference on Occupational Health, Seoul, Korea, 1979;253-7.

12 Matsumoto T, Yamada S, Harada N. A comparative study of vibration hazards among operators of vibration tools in certain industries. Arh Hig Rada Toksikol 1979;30[suppl]:701-7.

13 Suzuki H. Vibration syndrome of vibrating tool users in a factory of steel foundry. Part 2. Disturbances of the cutaneous senses and the blood flow of fingers. Jap J Ind Health 1978;20:269-75.

14 Verberk MM, Sallé HJA, Kempers O. Vibratory and tactile sense of the fingers after working with sanders. Int Arch Occup Environ Health 1985;56:217-23.

15 Sakurai T, Matoba T. Peripheral nerve responses to hand-arm vibration. Scand J Work Environ Health 1986;12:432-4.

16 Brammer AJ, Taylor W, Piercy JE. Assessing the severity of the neurological components of the hand-arm vibration syndrome. Scand J Work Environ Health 1986;12:428-31.

17 Ho ST, Yu HS. A study of neurophysiological measurements and various function tests on workers occupationally exposed to vibration. Int Arch Occup Environ Health 1986;58:259-68.

18 Andreeva-Galanina ET, Karpova NI. On degeneration and regeneration of peripheral nerves under the effect of experimental vibration. Gig Tr Prof Zabol 1969;13:4-7.

19 Karpova NI. Histopathology of the peripheral nerve stems subjected to the action of vibration. Arkh Patol 1963;7:49-53.

20 Takeuchi T, Imanishi H. Histopathologic observations in finger biopsy from thirty patients with Raynaud's phenomenon of occupational origin. Journal of the Kumamoto Medical Society 1984;58:56-70.

21 Walton $K$. The pathology of Raynaud's phenomenon of occupational origin. In: Taylor $\mathrm{W}$, ed. The vibration syndrome. London: Academic Press, 1974:113-5.

22 McDonald DM. Morphology of the rat carotid sinus nerve II. Number and size of axons. $J$ Neurocytol 1983;12:373-92.

23 Hiscoe HB. Distribution of nodes and incisures in normal and regenerated nerve fibres. Anat Rec 1947;99:447-75.

24 Behrens V, Taylor W, Wilcox T, et al. Vibration syndrome in chipping and grinding workers. $J$ Occup Med 1984; 26[suppl]:765-87.

25 Harada N, Matsumoto T. A study of various function tests on the upper extremities for vibration syndrome. Am Ind Hyg Assoc J 1981;42:887-92.

26 Starck K, Färkkilä M, Aatola S, Pyykkö I, Korhonen O. Vibration syndrome and vibration in pedestal grinding. $\mathrm{Br} J$ Ind Med 1983;40:426-33.

27 Kärosy T, Szepesi L. Effects of vibration exposure on the localization of Raynaud's phenomenon in chain saw operators. Work Environ Health 1973;10:134-9.

28 Wasserman DE. Raynaud's phenomenon as it relates to hand-tool vibration in the workplace. Am Ind Hyg Assoc J 1985;46:B10-8.

29 Taylor W, Wasserman D, Behrens V, Reynolds D, Samueloff S. Effect of the air hammer on the hands of stone cutters. The limestone quarries of Bedford, Indiana, revisited. Br J Ind Med 1984;41:289-95.

30 International Organisation for Standardisation. Guide for the measurement and the assessment of human exposure to vibration transmitted to the hand. Geneva: ISO, 1979. (ISO/DIS/5349.)

31 Takeuchi T, Futatsuka M, Imanishi H, Yamada S. Pathological changes observed in the finger biopsy of patients with vibration-induced white finger. Scand $J$ Work Environ Health 1986;12:280-3. 
32 Müller-Mohnssen H, Tippe A, Hillenkamp F, Unsöld E. Is the rise of the action potential at the Ranvier node controlled by a paranodal organ? Naturwissenshaften 1974;61:369-70.

33 Tippe A, Müller-Mohanssen H. Further experimental evidence for the synapse hypothesis of $\mathrm{Na}^{+}$current activation and inactivation at the Ranvier node. Naturwissenschaften 1975;62:490-1.

34 Schnapp B, Peracchia C, Mugnaini E. Freeze-fracture of Ranvier nodes. J Cell Biol 1973;59:360a.

35 Livingston RB, Pfenninger K, Moor H, Akert K. Specialized paranodal and interparanodal glial-axonal junctions in the peripheral and central nervous system: a freeze-etching study. Brain Res 1973;58:1-24.

36 Ellisman MH. High voltage electronmicroscopy of cortical specializations associated with membranes at nodes of Ranvier. J Cell Biol 1977;75:108a.

37 Ellisman MH. Molecular specializations of the axon membrane at nodes of Ranvier are not dependent upon myelination. $J$ Neurocytol 1979;8:719-35.

38 Wiley DA, Ellisman MH. Rows of dimeric-particles within the axolemma and juxtaposed particles within glia, incorporated into a new model for the paranodal glial-axonal junction at the node of Ranvier. J Cell Biol 1980;84:281-93.

39 Moore JW, Joyner RW, Brill MH, Waxman SD, Najar-Joa M. Simulations of conduction in uniform myelinated fibers.
Biophys J 1978;21:147-60.

40 Webster HdeF. The relationship between Schmidt-Lanterman incisures and myelin segmentation during Wallerian degeneration. Ann NY Acad Sci 1964;122:29-38.

41 Williams PL, Hall SM. Prolonged in vivo observations of normal peripheral nerve fibres and their acute reactions to crush and deliberate trauma. J Anat 1971;108:397-408.

42 Ganong WF. Review of medical physiology. 12th ed. Los Altos, California: Lange Medical Publications, 1985.

43 Guyton AC. Textbook of medical physiology, 6th ed. London: W B Saunders, 1981.

44 Futatsuka M, Pyykkö, Färkkilä M, Korhonen $\mathbf{O}$ Starck JP. Blood pressure, flow, and peripheral resistance of. digital arteries in vibration syndrome. Br J Ind Med 1983; 40:434-41.

45 Harada N, Matsumoto T. Validity of various function tests performed in Japan as a screening test for vibration syndrome. Int Arch Occup Environ Health 1984;54:283-93.

46 Färkkilä M, Pyykkö I. Blood flow in the contralateral hand duringf vibration and hand grip contractions of lumberjacks. Scand $J$ ? Work Environ Health 1979;5:368-74.

47 Färkkilä M, Pyykkö I, Korhonen O, Starck J. Vibration-induced $\vec{G}$ decrease in the muscle force in lumberjacks. Eur J Appl Physiol 1980;43:1-9. 